\title{
New Directions in the Assessment of Gastric Function: Clinical Applications of Physiologic Measurements
}

\author{
Jason Bratten Michael P. Jones \\ Division of Gastroenterology, Feinberg School of Medicine, Northwestern University, Chicago, III., USA
}

\section{Key Words \\ Gastric function testing - Scintigraphy - Stable isotope breath tests - Water and nutrient drink tests . \\ Electrogastrography · Ultrasound · Antroduodenal manometry $\cdot$ Magnetic resonance imaging $\cdot$ Single photon emission computed tomography}

\begin{abstract}
A variety of methods exist to assess gastric motor and sensory function. Specific techniques allow for the measurement of emptying, contractility, accommodation and sensation. Several of these techniques are suitable for in-office use rather than in a hospital or gastroenterology laboratory. While gastric function tests continue to proliferate and become more clinically accessible, their relevance to specific digestive symptoms or syndromes remains poorly studied. Additionally, the ability of gastric function testing to guide therapy or predict responses to interventions also remains poorly studied. Gastric function testing should be employed cautiously in clinical practice with an awareness that test results represent observations rather than diagnosis.
\end{abstract}

Copyright @ 2006 S. Karger AG, Basel

\section{KARGER}

Fax +4161306 1234

E-Mail karger@karger.ch

www.karger.com
(C) 2006 S. Karger AG, Basel

0257-2753/06/0244-0252\$23.50/0

Accessible online at: www.karger.com/ddi

\section{Introduction}

The stomach is responsible for storage, mixing, trituration and emptying. It also provides important sensory feedback regarding fullness and satiaton. Normal function allows the successful and generally pleasant ingestion of a variety of substances. Deranged gastric function can result in a wide range of unpleasant sensations and alter both the ability to pleasantly and successfully ingest. As gastric function is multifaceted and complex, a variety of tests are available to assess gastric function. This paper reviews currently available tests of gastric function.

When interpreting results of digestive function testing, it is essential to remember that digestive function is strongly influenced by both intrinsic and extrinsic factors. The central nervous system acting primarily through the autonomic nervous system and hypothalamic-pituitaryadrenal axis can greatly modify visceral function and sensation [1]. Additionally, disturbances in function of one digestive organ can, via enteric reflexes, result in alterations in function in other digestive structures [2, 3]. As such, an abnormal test of gastric function in the clinical arena should never be regarded as a diagnosis. Results of gastric function testing simply provide information that may inform the clinician of diagnostic possibilities. 


\section{Scintigraphy}

Scintigraphy remains the most widely studied and available method for measuring gastric emptying rates [4, 5]. The most commonly reported measurements from scintigraphic studies of gastric emptying are the percentage of gastric retention at specific time points after ingestion and the time required for half-emptying of the test meal $\left(T_{1 / 2}\right.$ or $\left.T_{50}\right)$. Also frequently reported is the time required for transfer of solid food from the fundus to the antrum and for the antrum to triturate the meal into a particle size $(<2 \mathrm{~mm})$ that can be emptied $\left(\mathrm{T}_{\text {lag }}\right)$. These parameters are variously calculated depending upon methods of image acquisition and the mathematical modeling assumptions used to estimate emptying [5].

Scintigraphy can also evaluation regional gastric function and antral motor activity. Dynamic antral scintigraphy can estimate both the frequency and magnitude of antral contractions. The magnitude of antral contractions has been shown to be increased in patients with functional dyspepsia and decreased in patients with diabetes [6, 7].

Scintigraphy has a number of pitfalls. There is radiation exposure. The test is time consuming for patients and medical staff. The radioisotope may separate from the test meal, migrate with the liquid phase of a meal producing falsely increased rates of gastric emptying. Clinically, the test is poorly standardized and this variability limits interpretation of results. Scanning times are also highly variable. Most centers scan continually for $90 \mathrm{~min}$, although a preferred method is to obtain static images at various time points. This approach is less labor intensive, more cost effective and provides results comparable to dynamic acquisition $[8,9]$. Gastric retention $>10 \%$ at $4 \mathrm{~h}$ has been shown to be highly predictive of gastric stasis [9]. Even when consistently performed, the coefficient of variation (the ratio of the standard deviation to the mean) is a substantial $15 \%[10]$.

\section{Stable Isotope Breath Tests}

Stable isotope breath tests use nonemitting isotopes to measure gastric emptying. The nonradioactive isotope, ${ }^{13} \mathrm{C}$, is usually bound to a medium chain triglyceride (octanoic acid) or proteinaceous algae (Spirulina), which is incorporated into a standardized test meal. The ${ }^{13} \mathrm{C}$-labeled substrate is ingested, emptied by the stomach and then absorbed in the proximal small intestine. Absorbed ${ }^{13} \mathrm{C}$ is metabolized in the liver to ${ }^{13} \mathrm{CO}_{2}$ and expired through the lungs. The test assumes that the rate-limiting

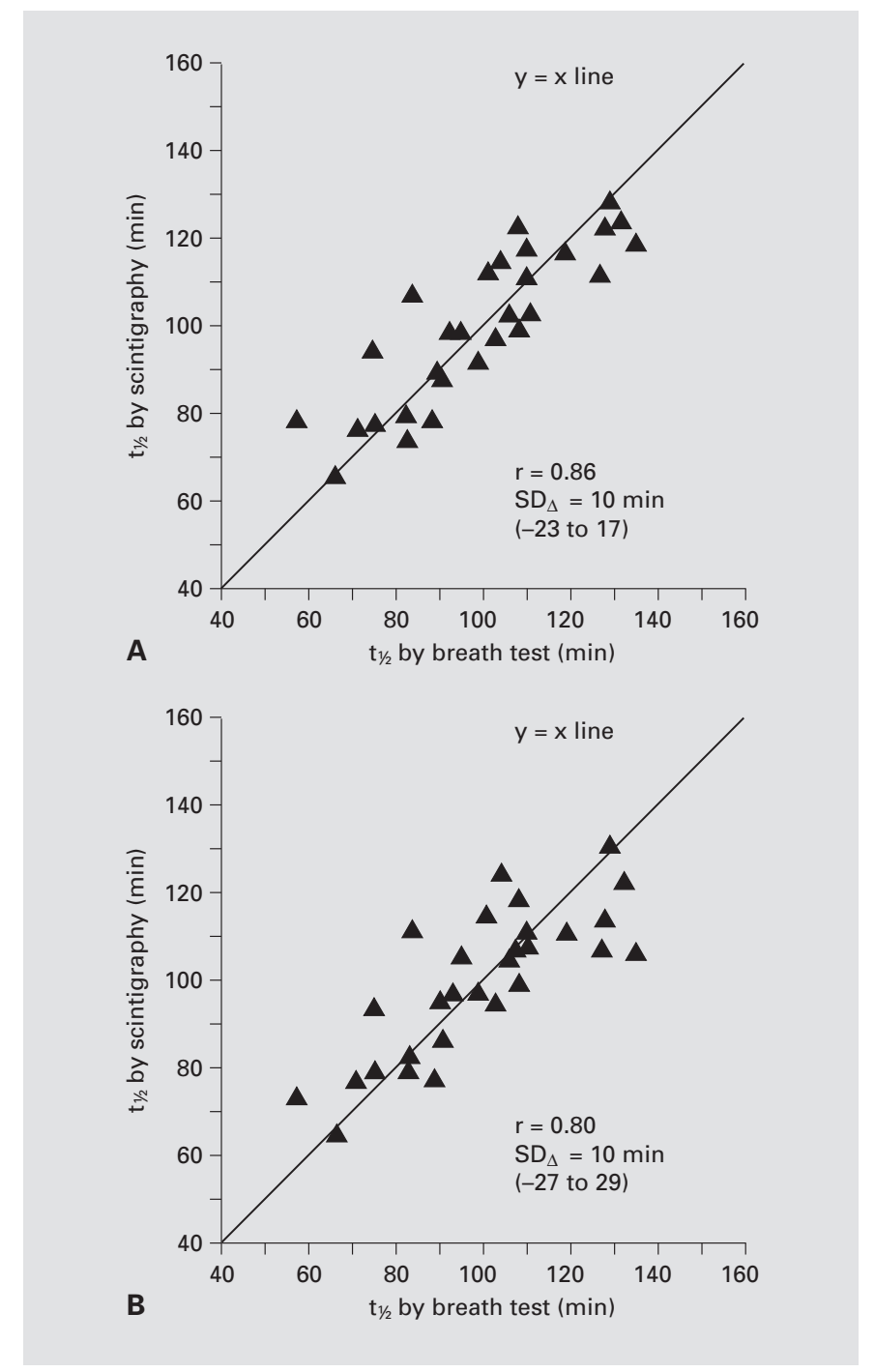

Fig. 1. Association between half-emptying times $\left(t_{1 / 2}\right)$ for scintigraphy values compared with estimates from a generalized linear regression model based on ${ }^{13} \mathrm{C}$-Spirulina breath test values from the first $3 \mathrm{~h}$ of data $(\mathbf{A})$ and for two time points from the first $3 \mathrm{~h}$ of sampling (B). The correlation between the methods is highly significant. The variation in differences between estimates by the two methods is expressed as SD (range). Adapted from Lee et al. [11].

step for excretion of ${ }^{13} \mathrm{CO}_{2}$ is gastric emptying [11]. Breath samples are collected at specific intervals for periods of up to 3-6 h. Enrichment of breath samples with ${ }^{13} \mathrm{CO}_{2}$ is determined by either isotope ratio mass spectrometry or laser infrared spectroscopy and this allows estimation of gastric emptying rates. Results from ${ }^{13} \mathrm{C}$ breath tests using labeled Spirulina, octanoate and acetate have all correlated well with simultaneously performed scintigraphic measures (fig. 1) [11-13]. 


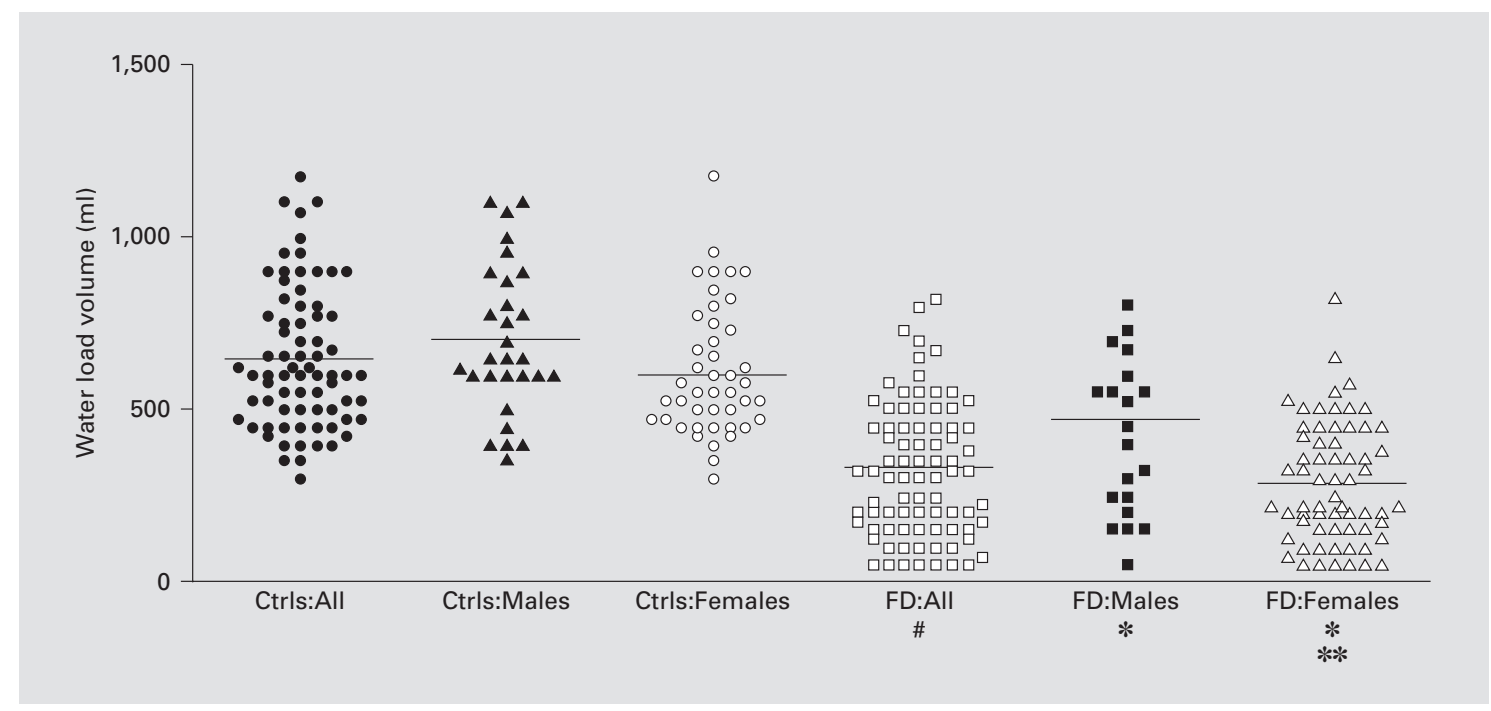

Fig. 2. Volumes required to produce satiety in healthy subjects and patients with functional dyspepsia using WL5. Male and female dyspeptics ingested significantly less water than healthy subjects. ${ }^{\#} \mathrm{p}<0.0001$ vs. controls; ${ }^{*} \mathrm{p}<$ 0.005 vs. controls of the same sex; ${ }^{* *} \mathrm{p}<0.0013$ vs. functionally dyspeptic males. Adapted from Jones et al. [14].

Stable isotope breath tests offer office-based, nonradioactive, standardized measures that potentially overcome the procedural variability seen with scintigraphy. Presently, breath samples are most often analyzed at a central facility, but office-based infrared spectroscopy units are increasingly available. Test results may be altered in patients with liver, pancreatic and pulmonary diseases as well as any condition altering intestinal absorption. Further validation studies are needed in patients with conditions known to accelerate or delay gastric emptying as most studies to date were performed in healthy subjects. If accuracy comparable to scintigraphy is confirmed in these conditions, stable isotope breath tests will offer a useful diagnostic alternative to scintigraphy.

\section{Water and Nutrient Drink Tests}

Drink tests developed as a noninvasive alternative to more invasive methods assessing sensory responses to gastric distension such as the barostat. A variety of methods have been proposed using either water or a variety of nutrient drinks consumed at either fixed rates or over ad libitum over a given interval [14-16]. No method has been proven superior, although the majority of investigators appear to favor nutrient-based drinks at present. Both water and nutrient drink tests are reproducible and consistently demonstrate that patients with functional dyspepsia report fullness at lower volumes than healthy subjects (fig. 2) [14]. Volumes to fullness with nutrient drink tests are not well correlated with volumes to fullness for water load tests [14].

The advantage of drink tests is that they are inexpensive and noninvasive. The disadvantage of drink tests is that no one is certain what exactly the drink test measures. Drink test volumes correlate poorly with SPECT and barostat-derived measures of gastric accommodation $[15,17]$. Drink test volumes and dyspeptic symptoms also poorly correlate, although an inverse correlation with nausea has been noted $[15,18,19]$. Presently, the drink test cannot be advocated as having value in the clinical arena and its investigational utility requires clarification.

\section{Electrogastrography}

The gastric pacemaker generates slow wave potentials at a frequency of $3 \mathrm{cpm}$. These slow waves lead to varying degrees of smooth muscle depolarization and potentially contraction. Abnormal pacemaker activity and neuromuscular function may result in changes in slow wave frequency with resultant alterations in gastric contractility. Electrogastrography (EGG) is a noninvasive method of recording gastric myoelectrical activity using cutaneous recording electrodes. These cutaneous recordings 
have been shown to correlate well with recordings made from serosal electrodes $[20,21]$. Abnormal gastric myoelectrical activity studied with EGG is reported in a variety of conditions including functional dyspepsia, motion sickness, a variety of disorders with nausea as a dominant symptom, gastroparesis of varying etiologies and mesenteric ischemia [22].

Equipment to perform EGG is commercially available. Recording and interpretation requires a certain degree of skill. Recordings are extremely susceptible to motion artifact so prolonged recordings or studies performed during other interventions are difficult to perform. Finally, as the American Motility Society has stated, 'the value of any diagnostic test is determined by its roles in directing therapy or providing prognostic information. To date, very few investigations have been performed to demonstrate a critical role for EGG in patient management' [22]. The technique will continue to be employed in an investigational setting, but until studies demonstrate the utility of EGG in improving treatment outcomes, there is little to recommend its clinical use.

\section{Ultrasound}

Ultrasonography has been used to evaluate gastric emptying, antral wall motion, transpyloric flow, and proximal stomach volumes [23-25]. Measurements are made relative to anatomic landmarks. Interobserver correlations are high [26]. Correlation with scintigraphic and stable isotope measures of gastric emptying is good [27, 28].

Ultrasound has the advantage of being widely available. As with any sonographic technique, body habitus and bowel gas may limit the study. Additionally, ultrasound does not lend itself well to prolonged studies. Presently, the technique is used in a few specialized centers. Studies demonstrating reproducibility and validity in more diverse practice settings are needed before the technique can fully endorsed.

\section{Antroduodenal Manometry}

Intraluminal pressure recordings from the antrum, pylorus and duodenum can be obtained using either waterperfused or solid-state catheters. Recording may be either stationary (typically several hours duration) or ambulatory. Antroduodenal manometry (ADM) assesses interdigestive and fed motor patterns. Ambulatory techniques allow for longer periods of recording and are best suited for assessment of interdigestive motility patterns, symptom-associated motility events and sleep-related motility changes [4]. Stationary studies are preferred when assessing antral responses to meals and antropyloroduodenal coupling.

ADM involves intestinal intubation and requires fluoroscopy for accurate catheter placement. While sedation can improve procedure tolerance of the procedure, commonly used medications may alter motility patterns. Use of reversal agents has been suggested but not studied [4].

ADM is most valuable when the study is normal. This excludes dysmotility as a symptom etiology. Other scenarios in which ADM may be helpful include suspected small bowel obstruction and detection of visceral myopathy. For gastric motility, ADM is rarely needed but can detect abnormalities associated with post-vagotomy syndromes, mechanical obstruction or rumination [29-31]. In children, the absence of migrating motor complexes has been shown to predict poor responses to enteral feeding and prokinetic therapy $[32,33]$. Such data are lacking in adults.

Overall, ADM is a technically challenging study requiring specialized equipment and expertise in performance and interpretation of studies. The procedure should be performed in centers with interest and experience in this technique.

\section{Magnetic Resonance Imaging}

Gastric emptying of both solids and liquids can be measured using MRI and the results correlate well with simultaneously performed scintigraphy [34, 35]. Preliminary data also support MRI in the measurement of gastric accommodation [36]. Gastric motility can also be evaluated using a real-time fast imaging sequence (fig. 3) [37]. MRI has also been used to evaluate intragastric distribution of drug models as well as to evaluate the motility responses of the stomach to various motility-modifying agents and meals [38-41].

One obvious advantage of MRI is the absence of radiation exposure. The technique also allows for repeated or prolonged observations, although procedure time currently restricts the migration of this technique from the research setting to the clinical realm. Additionally, studies must be performed supine which influences the mechanics of gastric emptying. Finally, confinement in the scanner can be unpleasant and the ability to breath-hold is required during image acquisition. 
Fig. 3. Two-dimensional real-time imaging in a healthy volunteer demonstrates motion of a peristaltic wave towards the pylorus (arrow). A-C Images are sequential. Adapted from Ajaj et al. [37].
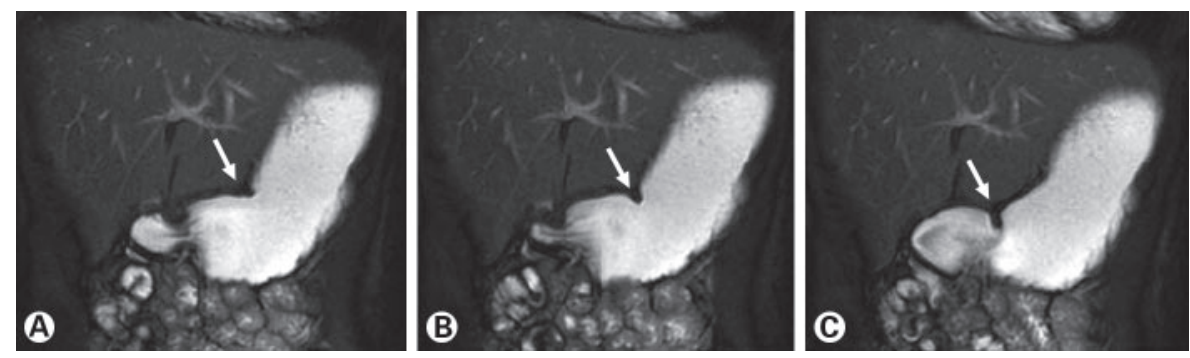

\section{Single Photon Emission Computed Tomography}

Single photon emission computed tomography (SPECT) is currently a research tool used to evaluate gastric accommodation. SPECT utilizes ${ }^{99 \mathrm{~m}}$ Tc-pertechnate which is taken up by the gastric mucosa (parietal and mucin-secreting cells). Tomographic images of the stomach are acquired with the patient in a supine position. SPECT has been shown to possess excellent intra- and interobserver agreement [42]. It is superior to balloon-based measures of accommodation since intubation is not required. However, a comparison of SPECT with barostat measurements showed poor correlation between the two techniques with respect to meal-induced accommodation (fig. 4) [43]. Barostat was also superior in assessing changes in gastric tone. Finally, barostat but not SPECT allows assessment of gastric sensory responses. While SPECT appears to be a robust and noninvasive method to measure gastric accommodation, further study is required to define its utility in research and clinical applications. If impaired accommodation can be shown to be a relevant pathophysiologic factor in functional dyspepsia, SPECT will no doubt assume an important role in the evaluation of that disorder.

\section{Other Tests of Interest}

\section{Gastric Emptying and Radiopaque Markers}

Several studies over the past decade have attempted to quantitate gastric emptying using various types of radiopaque markers (ROM) [44-48]. Emptying of indigestible ROM depends upon the successful initiation of a phase III contraction at the end of the fed period. In general, emptying of ROM correlates with gastric emptying measured either scintigraphically or sonographically [47, 48]. While appealing, this method is not standardized and poorly studied. The sensitivity and specificity of the

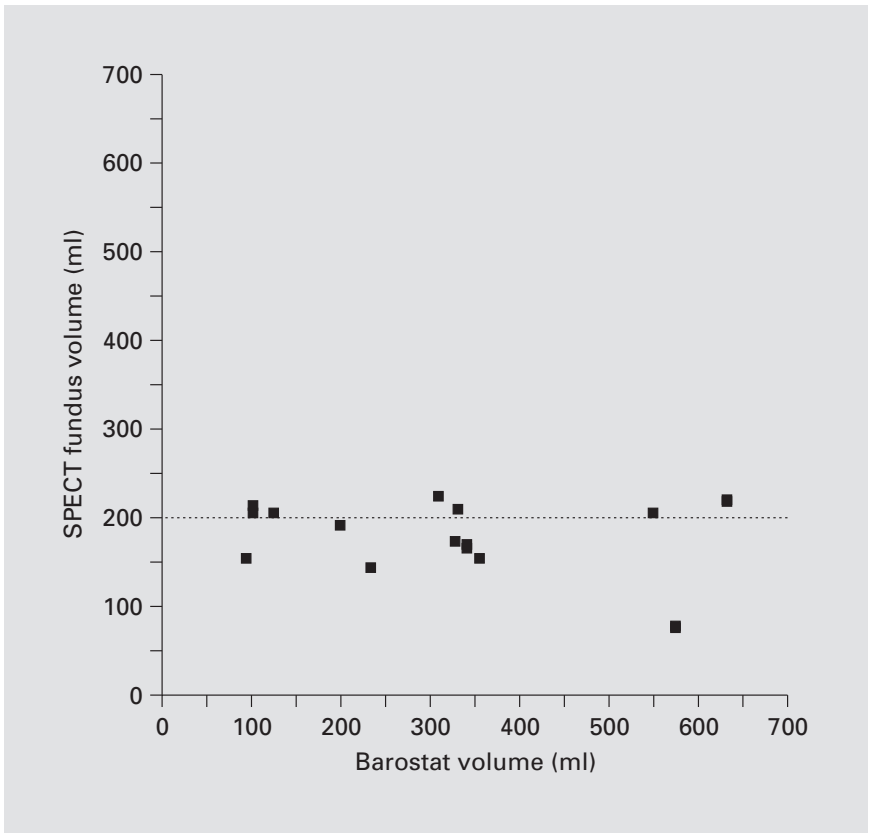

Fig. 4. Correlation plot between meal-induced accommodation assessed by single photon emission computed tomography (SPECT) scanning and barostat. Note that SPECT volumes are not significantly different from $200 \mathrm{ml}(\mathrm{p}=0.1)$, which equals the volume of the ingested meal. Adapted from van den Elzen et al. [43].

method needs to be determined. Finally, ROM methods require radiation exposure. Stable isotope breath tests will offer superior performance characteristics without radiation.

\section{Multichannel Intraluminal Impedance}

Multichannel intraluminal impedance has been studied extensively in the esophagus. The technique has also been successfully applied in assessing small intestinal transit [49]. At present, there are no published data evaluating this technique with respect to gastric motility beyond esophagogastric junction function. Multichannel 
Table 1. Clinical applicability of currently available gastric function tests

\begin{tabular}{|c|c|c|c|c|}
\hline Test & Measured parameter & $\begin{array}{l}\text { Radiation } \\
\text { exposure }\end{array}$ & $\begin{array}{l}\text { Performance } \\
\text { location }\end{array}$ & Clinical utility \\
\hline Scintigraphic gastric emptying & Gastric emptying & Yes & Radiology & $\begin{array}{l}\text { Usefulness of gastric emptying } \\
\text { data in guiding therapy and } \\
\text { predicting outcomes is uncertain }\end{array}$ \\
\hline Stable isotope breath tests & Gastric emptying & No & GI lab or office & $\begin{array}{l}\text { Usefulness of gastric emptying } \\
\text { data in guiding therapy and } \\
\text { predicting outcomes is uncertain }\end{array}$ \\
\hline Ultrasound & $\begin{array}{l}\text { 1. Gastric emptying } \\
\text { 2. Accommodation } \\
\text { 3. Transpyloric flow }\end{array}$ & No & Radiology & Currently investigational \\
\hline Drink tests & Unknown & No & GI lab or office & $\begin{array}{l}\text { No demonstrated clinical utility at } \\
\text { present time }\end{array}$ \\
\hline Antroduodenal manometry & $\begin{array}{l}\text { 1. Gastric and intestinal } \\
\text { contractions } \\
\text { 2. Antropyloroduodenal } \\
\text { coupling }\end{array}$ & Yes & GI lab & $\begin{array}{l}\text { Utility in adults unstudied but may } \\
\text { be of value when normal or } \\
\text { obstruction suggested. May help } \\
\text { predict responses to enteral feeding } \\
\text { and prokinetic therapy in children }\end{array}$ \\
\hline Magnetic resonance imaging & $\begin{array}{l}\text { 1. Emptying } \\
\text { 2. Antral contractions } \\
\text { 3. Accommodation }\end{array}$ & No & Radiology & Currently investigational \\
\hline $\begin{array}{l}\text { Single photon emission } \\
\text { computed tomography (SPECT) }\end{array}$ & Accommodation & Yes & Radiology & Currently investigational \\
\hline
\end{tabular}

intraluminal impedance may be of value in assessing transpyloric flow and duodenal-gastric reflux.

\section{Recommendations for the Use of Gastric Function Testing in Clinical Practice}

Reviewed diagnostic modalities are summarized in table 1 . While a wide variety of techniques are available to assess gastric motility and sensation, their relevance in clinical practice largely remains unproven. This statement is supported by three lines of evidence.

First, the association abnormal of gastric function with specific digestive symptoms or symptom complexes has not been conclusively demonstrated. Several investigators have reported an increased prevalence of gastric motor disturbances in patients with functional dyspepsia who have nonpainful symptoms such as nausea, bloating or early satiation $[50,51]$. Most of these reported asso- ciations are modest and a far larger body of evidence has failed to demonstrate consistent associations of gastric function testing with either specific symptoms or symptom subgroups of patients with functional dyspepsia [15, $19,52,53]$.

Second, abnormalities seen during gastric function testing may represent epiphenomenon rather than pathophysiologic determinants of symptoms. Examples of this include delayed gastric emptying in patients with anorexia nervosa [54], suppressed anger [55] and motion sickness [40]. This further emphasizes that the results of motility assessment represent an observation rather than a diagnosis.

Finally, the utility of currently available tests of gastric function to guide therapy or predict outcomes has not been conclusively established. While several studies have suggested that abnormal gastric emptying or EGG predicts a clinical response to cisapride [56-58], a recent systematic review has shown that there is a poor correlation between 
changes in rates of gastric emptying and symptom relief [59]. This is an area that demands further rigorous study.

In summary, a variety of techniques exist to assess various parameters of gastric motor and sensory function. While these techniques often provide accurate physiolog- ic assessment, the relevance of these measurements with respect to symptoms or guiding therapy remains largely unproven and understudied. Clinicians should employ these tests cautiously and be equally cautious in interpreting the results.

\section{References}

1 Mayer EA, Collins SM: Evolving pathophysiologic models of functional gastrointestinal disorders. Gastroenterology 2002;122:20322048.

$\checkmark 2$ Shafik A, Shafik AA, el-Sibai O: Study of the effect of jejuno-ileal distension on the motor activity of the stomach with evidence of 'entero-gastric inhibitory reflex'. Hepatogastroenterology 2003;50:1966-1969.

3 Coremans G, Geypens B, Vos R, et al: Influence of continuous isobaric rectal distension on gastric emptying and small bowel transit in young healthy women. Neurogastroenterol Motil 2004; 16:107-111.

$\checkmark 4$ Camilleri M, Hasler WL, Parkman HP, Quigley EM, Soffer E: Measurement of gastrointestinal motility in the GI laboratory. Gastroenterology 1998;115:747-762.

5 Mariani G, Boni G, Barreca M, et al: Radionuclide gastroesophageal motor studies. J Nucl Med 2004;45:1004-1028.

-6 Urbain JL, Vekemans MC, Bouillon R, et al: Characterization of gastric antral motility disturbances in diabetes using a scintigraphic technique. J Nucl Med 1993;34:576-581.

$\checkmark 7$ Ham HR, Muls V, Cadiere GB, Froideville JL, Urbain D: A radionuclide study of regional gastric motility. Nucl Med Commun 1995; 16 : 827-833.

8 Camilleri M, Zinsmeister AR, Greydanus MP, Brown ML, Proano M: Towards a less costly but accurate test of gastric emptying and small bowel transit. Dig Dis Sci 1991;36:609-615.

$\checkmark 9$ Tougas G, Eaker EY, Abell TL, et al: Assessment of gastric emptying using a low fat meal: establishment of international control values. Am J Gastroenterol 2000;95:1456-1462.

10 Degen LP, Phillips SF: Variability of gastrointestinal transit in healthy women and men. Gut 1996;39:299-305

11 Lee JS, Camilleri M, Zinsmeister AR, Burton DD, Kost LJ, Klein PD: A valid, accurate, office based non-radioactive test for gastric emptying of solids. Gut 2000;46:768-773.

$\checkmark 12$ Sutton DG, Bahr A, Preston T, Christley RM, Love S, Roussel AJ: Validation of the ${ }^{13} \mathrm{C}-o c$ tanoic acid breath test for measurement of equine gastric emptying rate of solids using radioscintigraphy. Equine Vet J 2003;35:2733.

$\checkmark 13$ Braden B, Adams S, Duan LP, et al: The $\left[{ }^{13} \mathrm{C}\right]$ acetate breath test accurately reflects gastric emptying of liquids in both liquid and semisolid test meals. Gastroenterology 1995; 108:1048-1055.
14 Jones MP, Hoffman S, Shah D, Patel K, Ebert $\mathrm{CC}$ : The water load test: observations from healthy controls and patients with functional dyspepsia. Am J Physiol 2003;284:G896G904.

15 Boeckxstaens GE, Hirsch DP, van den Elzen BD, Heisterkamp SH, Tytgat GN: Impaired drinking capacity in patients with functional dyspepsia: relationship with proximal stomach function. Gastroenterology 2001;121:10541063.

16 Tack J, Piessevaux H, Coulie B, Caenepeel P, Janssens J: Role of impaired gastric accommodation to a meal in functional dyspepsia. Gastroenterology 1998;115:1346-1352.

17 Gonenne J, Castillo EJ, Camilleri M, et al: Does the nutrient drink test accurately predict postprandial gastric volume in health and community dyspepsia? Neurogastroenterol Motil 2005; 17:44-50.

18 Boeckxstaens GE, Hirsch DP, Kuiken SD, Heisterkamp SH, Tytgat GN: The proximal stomach and postprandial symptoms in functional dyspeptics. Am J Gastroenterol 2002; 97:40-48.

19 Jones MP, Maganti K: Symptoms, gastric function, and psychosocial factors in functional dyspepsia. J Clin Gastroenterol 2004;38:866872.

20 Lin Z, Chen JD, Schirmer BD, McCallum RW: Postprandial response of gastric slow waves: correlation of serosal recordings with the electrogastrogram. Dig Dis Sci 2000;45:645-651.

21 Chen JD, Schirmer BD, McCallum RW: Serosal and cutaneous recordings of gastric myoelectrical activity in patients with gastroparesis. Am J Physiol 1994;266:G90-G98.

22 Parkman HP, Hasler WL, Barnett JL, Eaker EY: Electrogastrography: a document prepared by the gastric section of the American Motility Society Clinical GI Motility Testing Task Force. Neurogastroenterol Motil 2003; 15:89-102.

23 De Schepper HU, Cremonini F, Chitkara D, Camilleri M: Assessment of gastric accommodation: overview and evaluation of current methods. Neurogastroenterol Motil 2004;16: 275-285.

24 Berstad A, Hausken T, Gilja OH, Nesland A, Odegaard S: Imaging studies in dyspepsia. Eur J Surg Suppl 1998(582):42-49.

$\checkmark 25$ Berstad A, Hausken T, Gilja OH, Hveem K, Nesje LB, Odegaard S: Ultrasonography of the human stomach. Scand J Gastroenterol Suppl 1996;220:75-82.
26 Irvine EJ, Tougas G, Lappalainen R, Bathurst $\mathrm{NC}$ : Reliability and interobserver variability of ultrasonographic measurement of gastric emptying rate. Dig Dis Sci 1993;38:803-810.

$\checkmark 27$ Franke A, Harder H, Singer MV: Reliability of the $\left[{ }^{13} \mathrm{C}\right]$-acetate breath test in the measurement of gastric emptying of ethanol solutions: a methodological study. Scand J Gastroenterol 2004;39:722-726.

28 Holt S, Cervantes J, Wilkinson AA, Wallace $\mathrm{JH}$ : Measurement of gastric emptying rate in humans by real-time ultrasound. Gastroenterology 1986;90:918-923.

29 Fich A, Neri M, Camilleri M, Kelly KA, Phillips SF: Stasis syndromes following gastric surgery: clinical and motility features of 60 symptomatic patients. J Clin Gastroenterol 1990; 12:505-512.

30 O'Brien MD, Bruce BK, Camilleri M: The rumination syndrome: clinical features rather than manometric diagnosis. Gastroenterology 1995; 108:1024-1029.

31 Frank JW, Sarr MG, Camilleri M: Use of gastroduodenal manometry to differentiate mechanical and functional intestinal obstruction: an analysis of clinical outcome. Am J Gastroenterol 1994;89:339-344.

-32 Hyman PE, Di Lorenzo C, McAdams L, Flores AF, Tomomasa T, Garvey TQ 3rd: Predicting the clinical response to cisapride in children with chronic intestinal pseudo-obstruction. Am J Gastroenterol 1993;88:832-836.

33 Di Lorenzo C, Flores AF, Buie T, Hyman PE: Intestinal motility and jejunal feeding in children with chronic intestinal pseudo-obstruction. Gastroenterology 1995;108:1379-1385.

34 Schwizer W, Maecke H, Fried M: Measurement of gastric emptying by magnetic resonance imaging in humans. Gastroenterology 1992; 103:369-376.

-35 Feinle C, Kunz P, Boesiger P, Fried M, Schwizer W: Scintigraphic validation of a magnetic resonance imaging method to study gastric emptying of a solid meal in humans. Gut 1999; 44:106-111.

-36 Mearadji B, de Zwart I, Lamb H, Roos A, Masclee M, Kunz P: Assessment of gastric motility by combined real time MRI and barostat recording under fasting conditions. Gastroenterology 2001;120:A1485.

37 Ajaj W, Goehde SC, Papanikolaou N, et al: Real-time high-resolution magnetic resonance imaging for the assessment of gastric motility disorders. Gut 2004;53:1256-1261. 
38 Faas H, Steingoetter A, Feinle C, et al: Effects of meal consistency and ingested fluid volume on the intragastric distribution of a drug model in humans - a magnetic resonance imaging study. Aliment Pharmacol Ther 2002;16:217224.

39 Faas H, Schwizer W, Feinle C, et al: Monitoring the intragastric distribution of a colloidal drug carrier model by magnetic resonance imaging460. Pharm Res 2001;18:460-466.

40 Faas H, Feinle C, Enck P, Grundy D, Boesiger P: Modulation of gastric motor activity by a centrally acting stimulus, circular vection, in humans. Am J Physiol 2001;280:G850G857.

41 Borovicka J, Lehmann R, Kunz P, et al: Evaluation of gastric emptying and motility in diabetic gastroparesis with magnetic resonance imaging: effects of cisapride. Am J Gastroenterol 1999; 94:2866-2873.

42 Kuiken SD, Samsom M, Camilleri M, et al: Development of a test to measure gastric accommodation in humans. Am J Physiol 1999; 277:G1217-G1221.

$\checkmark 43$ Van den Elzen BD, Bennink RJ, Wieringa RE, Tytgat GN, Boeckxstaens GE: Fundic accommodation assessed by SPECT scanning: comparison with the gastric barostat. Gut 2003;52: 1548-1554.

44 Chang CS, Chen GH, Kao CH, Wang SJ, Poon SK, Lien HC: Correlation between patterns of antral contractility and gastric emptying of radiopaque markers. Am J Gastroenterol 1997; 92:830-834.
45 Horikawa Y: Gastric emptying of three different size of indigestible radiopaque markers in healthy subjects. J Smooth Muscle Res 1998; 34:83-88.

46 Kikuchi K, Kusano M, Kawamura O, Mori M, Sekiguchi T: Measurement and evaluation of gastric emptying using radiopaque barium markers. Dig Dis Sci 2000;45:242-247.

47 Loreno M, Bucceri AM, Catalano F, Blasi A, Brogna A: Gastric clearance of radiopaque markers in the evaluation of gastric emptying rate. Scand J Gastroenterol 2004;39:12151218 .

48 Stotzer PO, Fjalling M, Gretarsdottir J, Abrahamsson $\mathrm{H}$ : Assessment of gastric emptying: comparison of solid scintigraphic emptying and emptying of radiopaque markers in patients and healthy subjects. Dig Dis Sci 1999; 44:729-734.

49 Imam H, Sanmiguel C, Larive B, Bhat Y, Soffer E: Study of intestinal flow by combined videofluoroscopy, manometry, and multiple intraluminal impedance. Am J Physiol 2004;286: G263-G270.

50 Stanghellini V, Tosetti C, Paternico A, et al: Predominant symptoms identify different subgroups in functional dyspepsia. Am J Gastroenterol 1999;94:2080-2085.

-51 Fischler B, Tack J, De Gucht V, et al: Heterogeneity of symptom pattern, psychosocial factors, and pathophysiological mechanisms in severe functional dyspepsia. Gastroenterology 2003; 124:903-910.

52 Talley NJ, Verlinden M, Jones M: Can symptoms discriminate among those with delayed or normal gastric emptying in dysmotility-like dyspepsia? Am J Gastroenterol 2001;96:14221428
53 Bredenoord AJ, Chial HJ, Camilleri M, Mullan BP, Murray JA: Gastric accommodation and emptying in evaluation of patients with upper gastrointestinal symptoms. Clin Gastroenterol Hepatol 2003;1:264-272.

54 Benini L, Todesco T, Dalle Grave R, Deiorio F, Salandini L, Vantini I: Gastric emptying in patients with restricting and binge/purging subtypes of anorexia nervosa. Am J Gastroenterol 2004;99:1448-1454.

55 Bennett EJ, Kellow JE, Cowan H, et al: Suppression of anger and gastric emptying in patients with functional dyspepsia. Scand J Gastroenterol 1992;27:869-874.

56 Corinaldesi R, Stanghellini V, Raiti C, Rea E, Salgemini R, Barbara L: Effect of chronic administration of cisapride on gastric emptying of a solid meal and on dyspeptic symptoms in patients with idiopathic gastroparesis. Gut 1987;28:300-305.

57 Jian R, Ducrot F, Ruskone A, et al: Symptomatic, radionuclide and therapeutic assessment of chronic idiopathic dyspepsia. A doubleblind placebo-controlled evaluation of cisapride. Dig Dis Sci 1989;34:657-664.

58 Besherdas K, Leahy A, Mason I, Harbord M, Epstein O: The effect of cisapride on dyspepsia symptoms and the electrogastrogram in patients with non-ulcer dyspepsia. Aliment Pharmacol Ther 1998;12:755-759.

59 Sturm A, Holtmann G, Goebell H, Gerken G: Prokinetics in patients with gastroparesis: a systematic analysis. Digestion 1999;60:422427. 